\title{
Sports Participation and Social Personality Variable of Students in Secondary Schools in Central Senatorial District of Cross River State, Nigeria
}

\author{
Edim, M.E. ${ }^{1}$, Ekuri, P. K., Odok, E.A. \\ Department of Human Kinetics \& Health Education \\ Faculty of Education, University of Calabar, Calabar - Nigeria
}

\begin{abstract}
The main thrust of this study was to investigate sports participation and social personality variable of students in secondary schools in Central Senatorial District of Cross River State, Nigeria. To achieve the purpose of this study, one hypothesis was formulated to guide the study. Literature review was carried out according to the variable of the study. Survey research design was adopted for the study. A sample of five hundred (500) respondents was randomly selected for the study. The selection was done through the simple random sampling technique. The questionnaire was the instrument used for data collection. The reliability estimate of the instrument was established through the Cronbach Alpha reliability method. Independent t-test analysis was employed to test the hypothesis under study. The hypothesis was tested at .05 level of significance. The result of the analysis revealed that, there is a significant difference in the physical variables of secondary school students who participate and those who do not participate in sports. Based on the findings of the study, it was recommended that students should endeavor to take home the crusade of sports participation to further foster their interpersonal relationship with others around their neighborhood and community and again, the physical education teachers who are the custodians of sports in these schools, should make sure that every student takes active part in sports during training sessions.
\end{abstract}

\section{INTRODUCTION}

Sports are biological cum motor activities which enable an individual to develop and control his physique. It can also be described as activities involving physical exertion and skill in which an individual or team competes against another or for the purpose of entertainment. Nevertheless, the traditional view of sports participation is that, it has a beneficial effect on the social and moral development of children and young people. Sports may have the tendency if well organised to change the entire human personality (whole-man) through active and passive participation. Such components of personality that sports are capable of transforming include: physical, social, moral, mental, and emotional (Agbomi, 2012).

According to Edim (2011), sports can be termed as well organized and institutionalized physical activities with structured programmers' governed with rules and regulations. He further stressed that a good sports programme must be geared towards developing a 'whole-man' which is developing physically, socially skillfully, mentally, emotionally and morally individual (which is otherwise known as personality development) that is acceptable in the community and with good health.

Edim, Emeribe and Akah (2008), expressed that it is not an overstatement to remark that of all school subjects put together, sports alone can take a very prominent position in the educational system. Sports if properly harnessed, can contribute about fifty percent (50\%) or more to the educational goals of the society. They said, it is a well known fact that sports and recreation have been fundamental elements of the curricular of institutions throughout history. According to anthropological and historical researchers, physical education and sports are the most ancient subjects in humanities. From early to the present time, sports in one form or the other has been promoted by all fields of world civilization. It has received varying degrees of cultural and government emphasis and attention (Oyeniyi, 2001).

According to Edim (2008), one of the psychological constructs that lack precise and universally accepted definition is the term personality. Its problem of definition stems from two major factors. The first factor could be traced to diverse theoretical orientations of scholars of the concept who have put forward these definitions. This situation

${ }^{1}$ Corresponding Author: edimmoses@yahoo.com 


\section{American Research Journal of Humanities and Social Sciences, Volume 1, Issue 2, April 2015}

ISSN 2378-7031

gives room to multiplicity or irreconcilable definitions. The second factor is related to the etymology of the word personality.

Hans (1999) defined personality as the more or less stable and enduring organisation of a person's character, temperament, intellect, and physique which determines his unique adjustment to the environment. For the purpose of this research work, the researcher would consider the concept of personality as it concerns everything about an individual which include; the physical, social, mental, moral and emotional individual, and how these aforementioned components of personality have been improved upon through participation in sports.

\subsection{Sports Participation and Social Personality Variable of Students}

Leon (2006), opined that Sports for Social Development is a method of bringing about social changes through the use of sports. Most organizations utilizing this method are geared towards underprivileged children and teenagers in urban areas. The programs use sports to help children learn lifelong skills and as incentive for the children to improve their scholarship. The Sports for Development and Peace movement recognizes over 700 organizations working towards the goal of social change.

Sports as a universal language can be a powerful vehicle to promote peace, tolerance and understanding by bringing people together across boundaries, culture and religions. Government and international agencies are increasingly recognizing sports as an important powerful and unexploited tool for development in post-conflict reconstruction. In integrated programmes, sports can be used to attract young boys and girls away from the streets. Sport is an excellent "Training Ground for Democracy" and for promoting collective action. Its value also lies in drawing attention to the plight of refugees and internally displaced persons, helping to eliminate discrimination and stereotypes. Sport is an important component of culture. People express themselves and celebrate their communities through traditional sports and games. People share stoffes, myths, and lessons derived from sport. Through sport people learn values and behaviours that are applied to all aspects of society - hard work, discipline, the value of fun, teamwork, respect for others, and fair play (Hill \& Hansen, 2008).

Traditional games can be a prolific melting pot for people, groups and diverse communities belonging to different linguistic, religious and social backgrounds. These games can reflect diversity and cultural identities which can help bring people together and reduce prejudices. Their contribution to dialogue and fusion remains an asset within the framework of a culture of peace. People in every community across the continents follow teams and individuals from the local level to the world stage. Africans relax together over sport and it is often a shared topic of common interest.

Research also indicates that sports experiences foster citizenship, social success, positive peer relationships, and leadership skills (Evans \& Roberts, 2007). Youth sports and physical activity participation has been positively correlated with adult career achievement (Larson \&Verma, 2009) and negatively correlated with school dropout and delinquent behaviour (Segrave, 2009). Wankel (2010) highlighted that through sports, youth have opportunities to experience positive inter-group relations, community integration, social status, and social mobility, while Cote (2002) suggests that sport provides an arena for the development of social skills such as cooperation, assertion, responsibility, empathy, and self-control. Youth involved in sport often demonstrate discipline and commitment (Scanlan, 2011) preliminary evidence suggests that these traits carry over into other domains of life such as school and community (Carpenter, 2001).

\section{Methodology}

The research design that was used in this study is Survey design. The population of the study was three thousand four hundred and seven (3407) senior secondary school students from the Central Senatorial District of Cross River State, Nigeria. The simple random sampling technique was used to select 500 senior students for the study.

The research instrument used was the structured questionnaire, comprised of 16 items, all on a four Likert scale. In term of validity, some experts in measurement and evaluation and Human Kinetics and Health Education affirmed with $90 \%$ agreement that the entire instrument was suited for measuring what it purported to measure using the Cronbach Alpha reliability test. The reliability index of the entire instrument was found to be 0.86 . face-to-face hand delivery was method was used during the data collection procedure.

All the 500 copies of the questionnaire were retrieved and thus giving $100 \%$ return rate. The following hypothesis was tested in the study.

There is no significant difference in the social variables of students who participate in sports and those who do not participate. 


\subsection{Result of the Hypothesis}

This hypothesis states that there is no significant difference in the social variable of secondary schools students who participate in sports and those who do not participate. The dependent variable involved in this hypothesis is social variable, while the independent variable is sports participation which is categorized into two (those who participate and those who do not participate). Independent t-test analysis was employed to test this hypothesis. The result of the analysis is presented in Table 1.

Table1. Independent t-test analysis of the difference in social personality variable of secondary school students who participate and those who do not participate in sports $(N=500)$

\begin{tabular}{|l|l|l|l|l|}
\hline Sport participation & $\mathbf{N}$ & $\mathbf{x}-$ & SD & t-value \\
\hline Those who participate & 309 & 19.13 & 1.09 & \\
\hline Those who do not & 191 & 18.27 & 1.23 & $7.91^{*}$ \\
\hline Total & 500 & 18.80 & 1.98 & \\
\hline
\end{tabular}

*Significant at .05 level, $d f=498$, critical $t=1.96$

The result in the above table reveals that the calculated t-value of 7.91 is greater than the critical t-value of 1.96 at .05 level of significance with 498 degrees of freedom. With this result the null hypotheses was rejected. This implies that there is a significant difference in social variable of secondary school students who participate in sports and those who do not.

\section{DISCUSSION OF FINDINGS}

The result of this hypothesis indicated that there is a significant difference in the social variables of secondary school students who participate in sports and those who do not participate. The findings of this hypothesis is in agreement with the view of Leon (2006), who opined that Sports for Social Development is a method of bringing about social changes through the use of sports. Most organizations utilizing this method are geared towards underprivileged children and teenagers in urban areas. The programs use sports to help children learn lifelong skills and as incentive for the children to improve their scholarship. The Sports for Development and Peace movement recognizes over 700 organizations working towards the goal of social change.

Hill \& Hansen (2008) also maintained that sports as a universal language can be a powerful vehicle to promote peace, tolerance and understanding by bringing people together across boundaries, culture and religions. Government and international agencies are increasingly recognizing sports as an important powerful and unexploited tool for development in post-conflict reconstruction. In integrated programmes, sports can be used to attract young boys and girls away from the streets. Sport is an excellent "Training Ground for Democracy" and for promoting collective action. Its value also lies in drawing attention to the plight of refugees and internally displaced persons, helping to eliminate discrimination and stereotypes. Sport is an important component of culture. People express themselves and celebrate their communities through traditional sports and games. People share stuffs, myths, and lessons derived from sport. Through sport people learn values and behaviours that are applied to all aspects of society - hard work, discipline, the value of fun, teamwork, respect for others, and fair play.

Traditional games can be a prolific melting pot for people, groups and diverse communities belonging to different linguistic, religious and social backgrounds. These games can reflect diversity and cultural identities which can help bring people together and reduce prejudices. Their contribution to dialogue and fusion remains an asset within the framework of a culture of peace. People in every community across the continents follow teams and individuals from the local level to the world stage. Africans relax together over sport and it is often a shared topic of common interest.

Cote (2002) also suggests that sport provides an arena for the development of social skills such as cooperation, assertion, responsibility, empathy, and self-control. Youth involved in sport often demonstrate discipline and commitment. Preliminary evidence suggests that these traits carry over into other domains of life such as school and community. He also proposes that initiative, a key component to youths' positive social development, can also be developed through these structured activities. Given today's job demands and basic lifestyle requirements, Larson (2000) also argues that youth need to take charge of their lives through the development of initiative. Larson believes that initiative is constructed of three

key elements (intrinsic motivation, concerted engagement, and temporal effort directed towards a goal) and suggests that structured voluntary activities such as sports, arts, music, hobbies, and organizations offer the best contexts for 


\section{American Research Journal of Humanities and Social Sciences, Volume 1, Issue 2, April 2015 ISSN 2378-7031}

initiative development, as they are voluntary (require youth to be intrinsically motivated), require attention (elements of challenge), and require effort over time. He distinguishes how structured leisure activities such as sport (which requires attention and effort over time, and is voluntary), differs from school (which requires attention and effort over time, but is not voluntary), and television viewing (which is voluntary, but does not require attention or effort over time).

The increasing competitiveness in youth sports settings, coupled with the physical nature of sports, has led youth sports involvement to be linked to numerous negative social outcomes.

\section{CONCLUSION AND RECOMMENDATIONS}

Based on the result of the study the following conclusion was reached. There is a significant difference in the social variables of secondary school students who participate in sports and those who do not participate. Some recommendations were made:

Students should endeavour to take home the crusade of sports participation to further foster their interpersonal relationship with others around their neighbourhood and community.

The physical education teachers who are the custodians of sports in these schools, should make sure that every student takes active part in sports during training sessions.

$>$ A more regular inter-school sport competition programmes should be encouraged by the government to foster students' unity.

\section{REFERENCES}

[1] Agbomi, C. E. (2012). The role of sports in nation building. An unpublished seminar paper in CIINSTRID annual seminar, Calabar

[2] Carpenter, P. (2001). The importance of a church youth clubs' sport provision to continued church involvement, Journal of Sports and Social Issues, 25, 283-300.

[3] Co^te', J. (2002). Coach and peer influence on children's development through sports, in: J. M. Silva \& D. E. Stevens (Eds) Psychological foundations of sports (Boston, MA, Allyn\& Bacon), 520-527.

[4] Edim, M. E., Emeribe, V. C. \&Akah, L. U. (2008). Sports participation: A catalyst in health promotion and quality living.ICHPER-SD Africa Regional Congress Proceedings, University of Botswana, (pp.288 - 293) 14 - 17 October.

[5] Edim, M.E. (2011). Sports participation: A medium for health promotion and quality living.Journal of Sports Management and Education Research, 1(1) 51-59.

[6] Hans, V. (1999).Teacher Personality traits and characteristics and learning effectiveness of pupils.In C. G Asagwara (Ed).Psychological Perspective.Calabar: Psychological Productions and Services.

[7] Ndu, P. (2007).Physical activity and the initiation of high-risk health behaviors in adolescents.Journal of Medicine and Science in Sport and Exercise;27:1639-1645.

[8] Evans, J. \& Roberts, G. C. (2007).Physical competence and the development of children's peer relations, Quest, $39,25-35$.

[9] Hill, G. M. \& Hansen, G. F. (2008). Specialization in high school sports- the pros and cons, Journal of Physical Education, Recreation, \& Dance, (5), 76-79.

[10] Larson, R. W. \&Verma, S. (2009). How children and adolescents spent time across the world: work, play, and developmental opportunities, Psychological Bulletin, 125, 701-736.

[11] Larson, R. W. (2000). Toward a psychology of positive youth development, American Psychologist journal, 55, $170-183$.

[12] Leon, C. B. (2006). Strategies for effective sports management practices: Guides for sports managers and administrators. Lagos: Sports and Leisure Consults.

[13] Scanlan, T. K.(2011). An introduction to the sport commitment model, Journal of Sports and Exercise Psychology, 15, 115.

[14] Segrave, J. (2009). Sports and juvenile delinquency, in: R. Terjung, (Ed.) Exercise and sport science review. Vol. 11, 181192.

[15] Wankel, L. M. (2010). The psychological and social benefits of sport and physical activity, Journal of Leisure Research, (2), 167-182. 